\title{
Karol Baron: a little bit about him on his 70th birthday
}

\author{
Witold JarczYK AND JANusz MoraWiECD
}

\section{First contacts with Karol Baron}

WJ: For the first time I met Dr. Karol Baron at the very beginning of October 1975, when I was studying mathematics at the Faculty of Mathematics, Physics and Chemistry at the University of Silesia in Katowice, Poland, and he was giving classes on the theory of real functions there. Following the lecture of Professor Marek Kuczma he made use of the famous monograph [24] by Roman Sikorski, another distinguished Polish mathematician. That book contains a great number of nice and highly non-trivial exercises and the contact with them and the numerous attempts (not often successfull!) to solve them were one of my very first experiences with great mathematics. His calm questions "if somebody would like to present a solution of a problem" really stimulated us, a group of a few students. One semester later I was already invited by Professor Kuczma to join the Seminar on functional equations led by him. I am almost sure about the crucial role of Karol Baron while going about that business. It was the time of his long hair, cigarettes or a pipe, and sometimes even a barber could have a job with him.

JM: I met Doc. Karol Baron as a third-year master's degree student in 1984, when he was giving (together with prof. Marek Kuczma) a pro-seminar entitled Functional equations in a single variable. In the same academic year, I participated in his lecture on the theory of probability. I saw for the first time that a lecture could be like a mathematical book. It was split into smaller

It is a great pleasure for us to write a few sentences about Karol Baron, our teacher, master, colleague and then also a friend of us. Of course such a sentence may be treated as a polite but very trivial one which could begin almost every tribute to a distinguished colleague. In this case, however, there is no doubt that we are completely heart-to-heart: mature enough not to do mind opinions of our previous boss and supervisor. We both (WJ and JM) have different experiences when thinking about Karol, so the story runs in two parallel lines. 
parts with numbered definitions, theorems, lemmas and other facts. Moreover, all proofs were divided into numbered steps whose proofs were also numbered. It was quite easy to adapt this idea, but it was much harder to put it into practice. As yet, students' notes (currently in LaTeX) of that and other basic lectures are circulating in our Faculty. However, Karol Baron has not yet decided to write a script for students of that or any other lecture he has given, and there are really a lot of them. I liked the method of lecturing of Karol Baron so much that one day I asked him if he would agree to be a supervisor of my master's thesis. That is what happened and the next classes I had with him were seminars and monographic lectures, all on functional equations. I remember very well that at one of the seminars I gave a talk (one-semester long) on my master's thesis. The second (and the last) student who attended the same seminar was Roman Badora; now associate professor at the University of Silesia in Katowice. It was an interesting and important experience that provided the foundation and a good preparation for my future scientific work.

\section{How to become Karol Baron's Ph.D. student}

WJ: I graduated in 1978, with a master's degree in mathematics, under supervision of Marek Kuczma, and bargained for a position of assitant lecturer at the Faculty. Just after my master's exam he asked me a question whose importance I did not realize at that moment: "Do you prefer functional equations in a single variable, or those in several variables?". Having no idea about real differences between them I promptly answered "One variable would be definitely more interesting for me" hoping, of course, that this is just easier than doing research into functional equations in several variables. The next day Professor Kuczma informed me in a concise form that Dr Karol Baron will be my further supervisor. And so my wonderful adventure started.

JM: When in 1987 my master's thesis was almost completed, Karol Baron asked me what I thought about scientific work and joining the Department of Real Analysis headed by him. After the master's thesis defense I filled in the relevant documents and from October 1st 1987 I was employed as an assistant lecturer and my story with functional equations began. But before I was officially assigned to the Department of Real Analysis, Karol Baron asked me to give some serious consideration to my decision to work in his group, because he is not a member of the Polish communist party and for that reason I could face some troubles. One month before I started work, Karol Baron was assigned the position of director of the Institute of Mathematics of the University of Silesia.

\section{Under supervision of Karol Baron}

WJ: From the very beginning I was given a lot of attention by Karol Baron. Besides, this concerned not only me, his first Ph.D. student, but also each 
next one. Just before the summer vacation in 1978 he suggested examining two problems related to his research described in the paper [1] and in his habilitation thesis [2] but, simultaneously, pressed for not working too much during the holidays. He also recommended to read Kuczma's monograph [22] devoted to functional equations in a single variable. Its small and unique edition published in 1968 was then already completely unavailable in bookshops. It was only a few years later that he informed me about one of our colleagues wanting to sell it. I have this second-hand book to the present day.

JM: My way to Ph.D. was long and complicated, but Karol Baron always supported me. When I was still a student, Karol Baron proposed to me to investigate a functional equation introduced in [23] by a Swiss physicist Rolf Schilling in connection with his study of spatially chaotic structures in amorphous glassy materials. A few years later, he suggested that I look at a functional equation coming from game theory, handed over by Prof. Andrzej Lasota after one of the conferences. Getting a new result, I always came to Karol Baron describing what I had done. He asked for the proof, which was discussed in detail, but most of all he asked if I would like to drink tea. He brewed and even now he brews, although not as passionately as in the past, perfect tea. When my daughter had very serious health problems, he offered the help of one of his three brothers Jan Baron (now full professor and head of the Department of Radiology and Nuclear Medicine at the Medical University of Silesia and the Department of Radiology and Interventional Radiology at the University Clinical Center in Katowice). Let me thank both Jan Baron, a born doctor for helping my family ever since, and Karol Baron, who always said "family is the most important".

Boosting young people by encouraging them to read mathematical books and papers, simply to visit the mathematics library as often as possible, to be close to people wiser than us and not pressing too hard by asking every day "what about the problem that I posed yesterday?" this was and still is his way of treating his Ph.D. students but also all those who are interested in doing research, especially on mathematics.

\section{After Ph.D. but with care from Karol Baron}

WJ: Just after completing my Ph.D. Karol Baron said "Now you should apply for giving the course on mathematical analysis". His other words that were important to me in that moment were: "Now you should paddle your own canoe, you have no supervisor, no protector nor academic guide; you have only colleagues. Remember that your habilitation is only your business". No doubt karol inherited many such ideas from Marek Kuczma, his supervisor and great Master. Karol involved me also in some subsidiary tasks: collecting papers that could be candidates in the Kuczma Competition for the best Polish paper on functional equations, preparing a bibliography of works on functional equations in a single variable which was proposed by Professor János Aczél, and some 
editorial activities for the university publisher. Many times Karol warned me about doing my job: if you always do your best then people will depute further duties to you, more and more. It could seem that he was suggesting not to get the job well-done but it would be a false interpretation - everybody who is familiar with Karol Baron knows very well that he is as busy as Grand Central Station and, in addition, a real perfectionist.

JM: Not long after my doctoral defense Karol Baron told me more or less the same words that Witek had heard a few years earlier. It happened that I dropped into Karol Baron's office with a question about a spedific paper or some result that seemed useful at the moment. In such a situation, my question was never left unanswered. Sometimes after a few days he gave helpful information. One day I was offered the position of Deputy Dean of the Faculty of Mathematics, Physics and Chemistry. When I asked Karol Baron if I should agree, he replied "each of us has to do his duties here and if he does it sooner, the better for him". After a moment, he smiled and said "mainly we should beware of all those who want to be elected".

Karol Baron regularly visited our faculty reading-room. After staying for a while he usually distributed to us - the younger co-workers - titles of papers, which he came across while looking through the Mathematical Review and were strictly related to our currently conducted investigations. He always brought them on small pieces of paper, sometimes on used teabags or tram tickets. These were times without access to huge databases and unlimited online resources via the Internet. We will remember Karol as an almost perfect teacher - his lectures are always prepared admirably, given in a clear form with detailed proofs. Everybody who likes precision and lack of the waffle appreciates his lectures and classes. During the many years he presented a number of monographic lectures devoted to functional equations in one and several variables, methods of iterative functional equations, continuous solutions of functional equations and inequalities in several variables, functional equations with a convolution of the unknown function, regularly varying solutions of functional equations, Fortet-Mourier metric, vector measures and the spectral theorem, measure and category, Borel measures on metric spaces, linear-topological spaces, and others. The seminars for these lectures he usually left to us - the promoted doctors - each time asking if we were interested in them. The reason was always the same, as he repeated "the best way to study mathematics is by teaching".

\section{Department of real analysis: the greatest child of Karol Baron}

Karol Baron's whole professional life is mainly connected with the University of Silesia. He completed his Ph.D. under the supervision of Marek Kuczma 
January 16th, 1974. After his habilitation December 7th, 1980 he got a position of docent and since January 15th, 1999 he has been a full professor. For many years all those working on functional equations in Katowice were members of the Department of Functional Equations founded by Marek Kuczma, and after his stroke headed by Roman Ger. In 1986 Karol Baron decided to establish a new department, viz the Department of Real Analysis, and the Seminar on Real Analysis. He acted as their leader up to the end of June of 2014 when he passed both down to Janusz Morawiec. Apart from the three of us among their members were Marek Kuczma, up to his passing away, and former and present Ph.D. students of Karol Baron. The full list of those who obtained their doctoral degree under his supervision is:

Witold Jarczyk (1983)

Bolesław Gaweł (1993)

Janusz Walorski (1995)

Janusz Morawiec (1997)

Lech Bartłomiejczyk (2000)

Rafał Kapica (2003)

Dariusz Sokołowski (2006)

Wirginia Wyrobek-Kochanek (2012).

Rafał Kapica is now an assistant professor at the AGH University of Science and Technology in Kraków, Janusz Morawiec is an associate professor at the University of Silesia in Katowice and Witold Jarczyk is a full professor and has positions at the John Paul II Catholic University of Lublin and the University of Zielona Góra.

In 28 academic years Karol Baron conducted 743 meetings of the Seminar on Real Analysis with 584 talks. Some of them where very short and others pretty long; the complete list of all his talks is available on the web-page http:// www.math.us.edu.pl/zar/zar_sema.html.

\section{Mathematical interests of Karol Baron}

His main interests are in functional equations. A big part of his results (about 35 papers) deals with functional equations in several variables. In particular, they concern Cauchy, Pexider and Gołąb-Schinzel equations, Jensen convex functions, orthogonal additivity and the problem of improving the regularity of solutions to some classical equations as the translation equation and other equations of iteration theory. Let us mention only some of them $[6,8-$ 11,19]. What concerns iterative functional equations a number of his results is devoted to studying continuous solutions of nonlinear equations, including approximate solutions, the problem of extending solutions and nonlinear equations of infinite order. He is also interested in linear equations, especially 
those of integrated type which again are of infinite order. One of the crucial tools in studying these integrated linear equations is the notion of iteration of random-valued functions introduced in the paper [15] written jointly with Marek Kuczma, then studied in $[3,13]$ and applied, among others, in $[5,7,14,17,18]$. His mathematical interests are very wide. For example, paper [20], written jointly with Alice Simon and Peter Volkamnn, concerns a problem coming from an application in physics (see [21]). In the paper [16], which is a result of cooperation with Andrzej Lasota, he dealt also with asymptotic properties of Markov operators. Finally let us mention the survey paper [12] and its continuation [4].

Up to now Karol Baron has written more than 80 papers, some of them with co-authors. Among these 20 colleagues are: Witold Jarczyk, Peter Volkmann, Janusz Matkowski, Roman Ger, Alice Chaljub-Simon, Andrzej Lasota, Janusz Morawiec, Palaniappan Kannappan, Rafał Kapica, Jürg Rätz, Maciej Sablik, Marek Kuczma and others. It seems to me that after Marek Kuczma passed away two persons have been extremely important for Karol. They are Peter Volkmann from Karlsruhe and Andrzej Lasota in Katowice. No doubt they both had a great influence on him. Long discussions and short chats not only on mathematics, a great number of cups of tea, walks, jokes - all these were as important as mathematics, probably for each of them.

\section{Activities and duties of Karol Baron}

Since 1975 Karol Baron has been a member of the jury of the Kuczma Competition for the best Polish papers on functional equations and related topics. From 1981 up to 1987 he was the vice-director and then from 1987 up to 1992 the director of the Institute of Mathematics of the University of Silesia. Being the director he was the first to come to the institute, often as early as 7 a.m., and he was the last to leave at 7 or 8 p.m. In that time the Institute was the most important for him. He got used to doing his tasks himself and not offloading them on the shoulders of others; relying mainly on himself was his idée fixe. In the years 2003-2006 he was a member of the Mathematics Committee of the Polish Academy of Sciences. Since 2007 he has been a member of the editorial board of Opuscula Mathematica; previously he was a member of the editorial boards of: Aequationes Mathematicae (in the period from 1991 to 1996), Annales Mathematicae Silesianae (in the period 1997-2013) and Journal of Mathematics and Applications (in the period 2005-2015). He has written over 120 reviews for editorial offices of about 30 journals.

Finally some headwords that roughly but quite well characterize some other details of Karol's nature: lack of car, mobile phone and TV-set but a great esteem for mountain climbing and classical music including the opera-his office in the institute is full of music, not only mathematics. 


\section{Acknowledgements}

The research of the second author was supported by the University of Silesia, Mathematics Department (Iterative Functional Equations and Real Analysis program).

Open Access. This article is distributed under the terms of the Creative Commons Attribution 4.0 International License (http://creativecommons.org/licenses/by/4.0/), which permits unrestricted use, distribution, and reproduction in any medium, provided you give appropriate credit to the original author(s) and the source, provide a link to the Creative Commons license, and indicate if changes were made.

\section{References}

[1] Baron, K.: On the continuous solutions of a non-linear functional equation of the first order. Ann. Polon. Math. 28, 201-205 (1973)

[2] Baron, K.: Functional equations of infinite order, Prace Naukowe Uniwersytetu Śląskiego w Katowicach 265, Uniwersytet Śląski, Katowice (1978)

[3] Baron, K.: On the convergence of sequences of iterates of random-valued functions. Aequ. Math. 32, 240-251 (1987)

[4] Baron, K.: Recent Results in a Theory of Functional Equations in a Single Variable, Series Mathematicae Catoviciensis et Debreceniensis (Seminar LV), vol. 15 http://www. math.us.edu.pl/smdk/papers2.html (2003)

[5] Baron, K.: Linear iterative equations of higher orders and random-valued functions. Publ. Math. Debr. 75, 1-9 (2009)

[6] Baron, K.: On Baire measurable solutions of some functional equations. Cent. Eur. J. Math. 7, 804-808 (2009)

[7] Baron, K.: On the convergence in law of iterates of random-valued functions. Aust. J. Math. Anal. Appl. 6(1), 9 (2009). Art. 3

[8] Baron, K.: On additive involutions and Hamel bases. Aequ. Math. 87, 159-163 (2014)

[9] Baron, K.: Orthogonally additive bijections are additive. Aequ. Math. 89, 297-299 (2015)

[10] Baron, K.: On the set of orthogonally additive functions with orthogonally additive second iterate. Aequ. Math. 91, 995-1000 (2017)

[11] Baron, K., Chojnacki, W., Jarczyk, W.: Continuity of solutions of the translation equation. Aequ. Math. 74, 314-317 (2007)

[12] Baron, K., Jarczyk, W.: Recent results on functional equations in a single variable, perspectives and open problems. Aequ. Math. 61, 1-48 (2001)

[13] Baron, K., Jarczyk, W.: Random-valued functions and iterative functional equations. Aequ. Math. 67, 140-153 (2004)

[14] Baron, K., Kapica, R.: A uniqueness-type problem for linear iterative equations. Analysis (Munich) 29, 95-101 (2009)

[15] Baron, K., Kuczma, M.: Iteration of random-valued functions on the unit interval. Colloq. Math. 37, 263-269 (1977)

[16] Baron, K., Lasota, A.: Asymptotic properties of Markov operators defined by Volterra type integrals. Ann. Polon. Math. 58, 161-175 (1993)

[17] Baron, K., Morawiec, J.: Lipschitzian solutions to linear iterative equations. Publ. Math. Debr. 89, 277-285 (2016)

[18] Baron, K., Morawiec, J.: Lipschitzian solutions to linear iterative equations revisited. Aequ. Math. 91, 161-167 (2017)

[19] Baron, K., Rätz, J.: On orthogonally additive mappings on inner product spaces. Bull. Pol. Acad. Sci. Math. 43, 187-189 (1995) 
[20] Baron, K., Simon, A., Volkmann, P.: Solutions d'une équation fontionnelle dans l'espace des distributions tempérées. C. R. Math. Acad. Sci. Paris 319, 1249-1252 (1994)

[21] Derfel, G., Schilling, R.: Spatially chaotic configurations and functional equations with rescaling. J. Phys. A 29, 4537-4547 (1996)

[22] Kuczma, M.: Functional Equations in a Single Variable. Monografie Mat. 46, PWNPolish Scientific Publishers, Warszawa (1968)

[23] Schilling, R.: Spatially chaotic structures. In: Thomas, H. (ed.) Nonlinear Dynamics in Solids, pp. 213-241. Springer, Berlin (1992)

[24] Sikorski, R.: Funkcje rzeczywiste, tom I, Monografie Mat. 35, Państwowe Wydawnictwo Naukowe, Warszawa, (1958) [in Polish]

Witold Jarczyk

Instytut Matematyki i Informatyki

Katolicki Uniwersytet Lubelski Jana Pawła II

Konstantynów $1 \mathrm{~h}$

20-708 Lublin

Poland

e-mail: wjarczyk@kul.lublin.pl;

w.jarczyk@wmie.uz.zgora.pl

and

Wydział Matematyki, Informatyki i Ekonometrii

Uniwersytet Zielonogórski

Szafrana $4 \mathrm{a}$

65-516 Zielona Gora

Poland

Janusz Morawiec

Instytut Matematyki

Uniwersytet Śląski

Bankowa 14

40-007 Katowice

Poland

e-mail: morawiec@math.us.edu.pl

Received: June 20, 2018

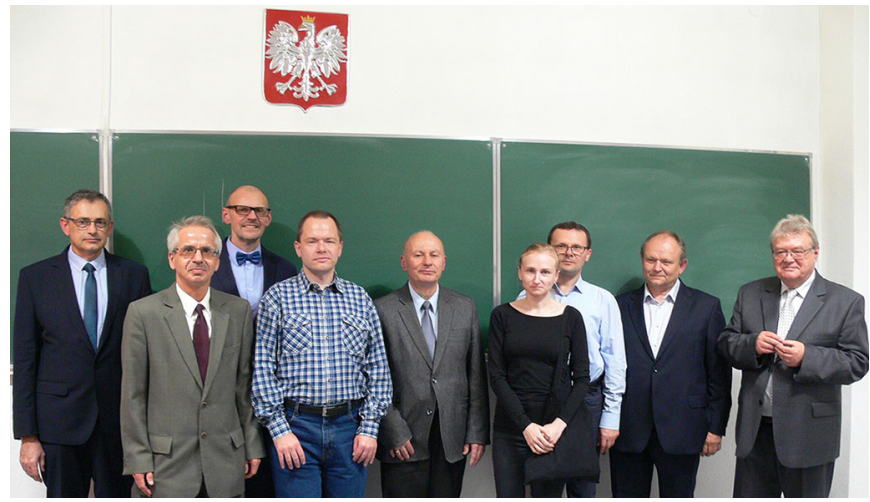

